London, UK

stephen.armstrong@me.com

Cite this as: BMJ 2021;374:n1732 http://dx.doi.org/10.1136/bmj.n1732 Published: 15 July 2021

\section{HEALTH EQUITY}

\section{Universal access to the digital NHS-but only if you have a smartphone}

\author{
As covid-19 accelerates the NHS's shift to a high tech future, Stephen Armstrong considers the \\ patients being left behind by the digital gold rush
}

\section{Stephen Armstrong freelance journalist}

The pandemic has already substantially worsened existing health inequalities, says Helen Barnard, director of poverty research charity the Joseph Rowntree Foundation. "We came into covid-19 with the grim statistic that a baby girl born in the poorest part of the country could expect to live in good health for 51 years and poor health for 21, while a girl born in the richest part could live 71 healthy years and 15 years in poor health," she says.

"Under covid-19, better paid jobs were more likely to accommodate working from home, while poorly paid jobs were more likely to expose people to the virus at work. Rent arrears built up, creating stress, anxiety, and depression. This translated into a big picture of deaths from covid-19 in deprived communities, which was even worse for people in ethnic communities.

"Digital exclusion has made that worse: it's harder to access what support is out there if a parent has two kids trying to home school using the limited data on their smartphone."

\section{Accelerating NHS transformation}

“Digital government-the ongoing use of digital technology and techniques to transform how government delivers public services, provides information, and functions as an organisation-has played a key part in the [pandemic] response, ensuring the continuity of existing services and the creation of new ones," wrote the Institute for Government think tank last year. ${ }^{1}$

The NHS app already enabled patients with smartphones to check symptoms, book appointments, order repeat prescriptions, and access their medical records before it became a potential "covid-19 passport" to show vaccination status and recent test results. ${ }^{2}$ The government heralded the NHS Covid 19 Track and Trace app as central to reopening hospitality venues as lockdown restrictions eased.

In the early days of the pandemic, general practice transformed, "rapidly adopting digital approaches to triaging and consulting at a speed that would have been unthinkable just months before," said the King's Fund think tank in February. ${ }^{3}$ Face-to-face GP consultations became "out of date almost overnight," Mark Harmon, a general practitioner and strategic director of the digital triage tool eConsult, told The $B M J$. He cited one general practice, Beacon Medical Group in Devon, that reduced its face-to-face appointments to just $7 \% .^{4}$
This digital gold rush, however, is in danger of dismantling one of the founding principles of the NHS-equal access to the health system for all.

\section{Lack of broadband}

It's hard to get accurate figures on the scale of digital health inequity. The Health Foundation, a think tank, found that about three fifths of NHS users increased their use of technology to access care in the first phase of the pandemic, in a representative survey of 4000 UK adults. Although $83 \%$ viewed their experience positively, $42 \%$ said the use of technology made for worse quality of care. ${ }^{5}$

Ofcom says that only 6\% of UK homes (roughly 1.5 million) have no internet access. ${ }^{6}$ But the Ida Lovelace Institute, which was established "to ensure that data and AI work for people and society,"7 found that a fifth of people in the UK do not have access to a smartphone, and $14 \%$ do not have broadband internet. The nationally representative survey it have not heard of symptom tracking apps, and just over half have not heard of the availability of online medical appointment services. A similar proportion think it is likely that vaccine passports would lead to discrimination against marginalised groups.

“We've heard from lots of older people who can't engage with things like eConsult," says Caroline Abrahams, charity director at Age UK. "They're not digital savvy, they're not online, they don't have broadband. Practices that shifted from the default of seeing people face to face are not meeting the needs of older people. Lots of people tell us that they have not anti-tech. We see it has benefits and works well. But the point is that it's supposed to be expanding choice not denying access."

Newspapers have even reported older customers being turned away from pubs for not having the Track and Trace smartphone app, despite no government requirement to use it. ${ }^{89}$

\section{"Shouting at the screen"}

The mental health dimension of the pandemic is not something technology is equipped to help with, says Helen Milner, group chief executive of the charity the Good Things Foundation. "For people who are able to use technology, shifting everyday life online has been strange and unexpected, but not exactly a leap in the dark. For those millions who can't, the lockdown has meant being literally cut off from the commissioned also found that $60 \%$ of the UK public just given up trying to access primary care. We are 
world and essential services-leading to loneliness and social isolation."

\section{Sharon McAulay, manager of the STAR Project in Paisley, a} community organisation working to build safer, more connected, and more resilient families, has found that technology limits the team's ability to help service users. "People are reporting trauma," she explains. "Nobody has had a chance to express their fears to support services. We have seen an increase in suicides. People who were just managing are now falling into the group of need and not knowing who to talk to and where to go. The Scottish government has given out laptops but no training or money to help people learn how to do it. We had a recent wellbeing workshop online, and people were unravelling so quickly it became two hours of people crying and shouting at the screen."

As lockdown lifts and life returns to normal, McAulay predicts a mental health pandemic as individuals and communities struggle to recover. According to research by Stephanie van Goozen, director of the neurodevelopment assessment unit at Cardiff University, the pandemic has already increased mental health problems and potentially damaged the development of children aged 4-7 in families whose financial circumstances have been seriously affected by lockdown.

"This is the age when kids develop crucial cognitive skills such as language development and key emotional skills," van Goozen says. "We also found high levels of stress and anxiety. These were homes where online teaching was hard to access. Since restrictions began to ease, we have seen that parents are catching up, and, for many, kids being back at school means things are getting better, but for those vulnerable children things have not improved-in fact, they have got worse. We will probably see that it is a truly high risk group, which is affected in the long term. It might take years for them to recover."

\section{Dangers of technophilia}

In April, the UK government published its Covid-19 Mental Health and Wellbeing Recovery Action Plan, including a £2.5m (€2.9m; \$3.5m) Digital Lifeline fund to provide tablets and digital support to about 5000 people with learning disabilities in England.

Employment programmes have been encouraged to use digital and telephone channels rather than face-to-face contact as the recovery gathers pace. For many commentators, this suggests that the health problems of digital inequality will increase.

"Any digital interface has built into it a number of assumptions-some are inclusive and some excluding and stratifying, often without anyone meaning them to be," says Clare Birchall, author of Shareveillance: The Dangers of Openly Sharing and Covertly Collecting Data and reader at King's College London. "The technophilia and mass digitisation of all government services-including the health service-has to go at a pace at which all of society, including the poorest and the least media literate, can manage. Otherwise we run the risk of permanently breaking one of the fundamental principles of the NHS-that is, equality of access.”

\section{Deaf patients excluded}

Even when patients do access primary care digitally, some are receiving poorer care as the result of disability. Office for National Statistics figures published in February showed that 6 of 10 people who died with covid-19 were disabled. ${ }^{10}$ In November 2020 a report funded by the US Agency for Healthcare Research and Quality and the National Institutes of Health ${ }^{11}$ warned that video calls made it harder for people with communication related disabilities such as deafness, blindness, and speech disabilities to access healthcare.

"Lots of general practices insist on communicating by phone in the pandemic," Jean Straus, patient advocate, especially for hearing loss, told The BMJ by phone. "The fact that I can speak with you now is thanks to Bluetooth streaming to my hearing aid. I can speak to GPs using that mechanism, but you have to be assertive to get the technology you need and know what that technology is. Health services that remain telephone only or telephone first remain difficult or impossible for deaf people. How do you book or change an appointment?"

The Royal College of General Practitioners' current covid-19 advice, taken from the Royal National Institute for Deaf People's communication tips for health and social care professionals, ${ }^{12}$ suggests that doctors "ask for and meet communication needs where possible. Instead of using the telephone, where possible use video conferencing tools and add live captioning through video conferencing software."

"Sign language is a 3D language-it does not benefit from being on flat screen," explains James Watson O'Neill, chief executive of deaf led healthcare charity SignHealth. "It disadvantages deaf people to be asked to communicate in a way that doesn't respect the language."

More than 70 ooo deaf people across the UK use British sign language to communicate. Deaf people's health is already much poorer than hearing people's, and deaf people often rely on family and friends to interpret for them at doctors' appointments, but social distancing and stay at home policies made that difficult. There are roughly 1000 qualified registered interpreters in the country, according to SignHealth, and few of them are in rural areas.

In April 2020, SignHealth launched British Sign Language Health Access for on demand access to video sign language interpreters in health settings free of charge. SignHealth spent $£ 800000$ of its financial reserves in the first three months before the NHS agreed to cover the running costs from December to the end of March 2021. ${ }^{13}$ Funding ran out in March, and the service is now closed.

For deaf patients and healthcare professionals, personal protective equipment can make lip reading impossible. Research by deaf professionals into the provision of transparent or accessible face masks for colleagues found that just $11 \%$ of those polled had access to transparent masks. ${ }^{14}$

\section{Literacy matters more than digital access}

Laurie McCusker, director of community organisation the Fermanagh Trust in rural Fermanagh, has found that digital uptake is not an accurate measure of the problems people face accessing healthcare online. "The solution to the digital divide is not broadband capacity and handing out machines-that's part of the solution, but it will not assist or support the significant percentage of people who have poor or low level literacy skills," McCusker explains.

One in six adults in England, or 7.1 million people, have very low literacy skills as defined by the UK National Literacy Trust. ${ }^{15}$ One in four adults in Scotland, one in eight in Wales, and one in five in Northern Ireland also experience severe challenges in reading and writing.

"In Fermanagh we have discovered that a higher percentage of people who are isolated have low literacy skills," McCusker explains. "These people can't use online health information or support even if they have access to it-and they are more likely to suffer from loneliness. We have to get back to basics if we are not going to leave millions of people behind."

McCusker's trust contacts isolated individuals across the rural county to check in and provide conversation and human contact. "We have 40 volunteers calling roughly 70 people twice a week," he explains. "There are no qualifications - the referrals come from different places including self-referral. An important percentage have challenging mental health issues-that's part of isolation and loneliness as well. We know that some of the befrienders are lonely too, including one lady on dialysis four days a week, so the volunteer gets as much out of it as the befriended." 
Provenance and peer review: Commissioned; not externally peer reviewed.

Competing interests: I have read and understood BMJ policy on declaration of interests and have no relevant interests to declare.

1 Institute for Government. Digital government during the coronavirus crisis. 2020

https://www.instituteforgovernment.org.uk/sites/default/files/publications/digital-governmentcoronavirus.pdf

2 Downey A. NHS App to be used as Covid-19 passport, transport secretary confirms. Digitalhealth 2021 Apr 28. https://www.digitalhealth.net/2021/04/nhs-app-to-be-used-as-covid-19-passporttransport-secretary-confirms/

3 Baird B. What enabled rapid digital change in primary care during the Covid-19 pandemic? King's Fund. 10 Feb 21. https://www.kingsfund.org.uk/blog/2021/02/rapid-digital-change-primary-carecovid-19-pandemic

4 Ford P. Digital triage changes the game for UK GP practices in the age of covid-19. Mobi Health News 2020 May 5. https://www.mobihealthnews.com/news/emea/digital-triage-changes-gameuk-gp-practices-age-covid-19

5 Health Foundation. Poll reveals positive experience of NHS tech during COVID, but public not yet sold on future use. $16 \mathrm{Mar}$ 2021. http://health.org.uk/news-and-comment/news/poll-revealspositive-experience-of-nhs-tech-during-covid-19

6 Ofcom. Digital divide narrowed by the pandemic, but around 1.5m homes remain offline. $28 \mathrm{Apr}$ 2021. https://www.ofcom.org.uk/about-ofcom/latest/features-and-news/digital-divide-narrowed but-around-1.5m-homes-offline

7 Ada Lovelace Institute. The data divide. 25 Mar 2021. https://www.adalovelaceinstitute.org/survey/data-divide/

8 Sales D. Middle-aged customers claim they are being embarrassed by "young and arrogant" bar staff who turned them away for not having the NHS Covid-19 app (despite rules saying they don't need one). Daily Mail 2020 Sep 29. https://www.dailymail.co.uk/news/article8785123/Customers-embarrassed-young-arrogant-bar-staff-Covid-app.html

9 Smith R. Partially blind man unable to complete Track \& Trace form "refused entry" into Wellington pub, which they deny. Shropshire Star 2021 Oct 14. https://www.shropshirestar.com/news/health/coronavirus-covid19/2021/02/23/partially-blind-man-unable-tocomplete-track-trace-form-refused-entry-into-wellington-pub-which-they-deny/

10 Office for National Statistics. Updated estimates of coronavirus (covid-19) related deaths by disability status, England: 24January to 20 November 2020. https://www.ons.gov.uk/peoplepopulationandcommunity/birthsdeathsandmarriages/deaths/articles/coronaviruscovid19relateddeathsbydisabilitystatusenglandandwales/24januaryto20november2020

11 Valdez RS, Rogers CC, Claypool H, etal Ensuring full participation of people with disabilities in an era of telehealth. 2021;28:389-92.

12 Royal National Institute for Deaf People. Communication tips for health and social care professionals. https://rnid.org.uk/wp-content/uploads/2021/02/CommunicationTips.pdf

13 SignHealth. BSL health access for the UK's Deaf community. Apr 2020. https://signhealth.org.uk/resources/bs/healthaccess/

14 Grote $\mathrm{H}$, Izagaren $\mathrm{F}$, Jackson $\mathrm{E}$. The experience of $\mathrm{D} /$ deaf healthcare professionals during the coronavirus pandemic. Occupational Med 2021;kqab048

15 National Literary Trust. Adult literacy. https://iteracytrust.org.uk/parents-and-families/adult-literacy/

16 Cabinet Office, Department of Health and Social Care. Covid-19 mental health and wellbeing recovery action plan. Apr 2021. https://www.gov.uk/government/publications/covid-19-mentalhealth-and-wellbeing-recovery-action-plan 